Reporting Duie: July 1974

Issued: December 1974

\title{
Semiempirical Cable Design
}

by

G. P. Boicourt 
Printed in the United Strte of Amorica. Arediable trom National Techniad laformation Servios

U.S. Deportenent of Commeros

578s Pat Royal Rood

Price: Prinind Copr \$A.0 Micuoliahe 12.25

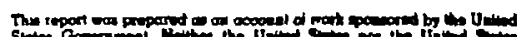

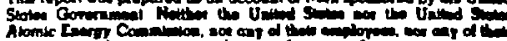

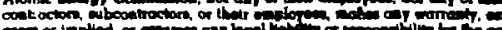

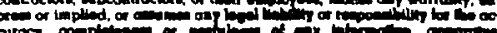

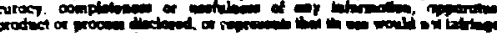

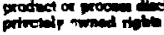




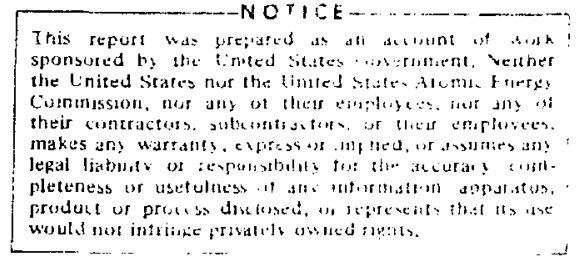

SEMIEMPIRICAL CABLE DESIGN

by

G. P. Boicourt

\section{ABSTRACT}

Coaxia? cables are used extensively on Control led Thermonuciear Research (CIR) at yoltages much higher than mariufacturers' ratings. The question of how such a cable should be designed is not easily answered. This report describes an approach to the problem that combines empirical knowledge ano mathematical analysis. The result is an algorithm that will compute the optimal cable size for a cable having a given inductance, a given peak operating voltage, and a given maximum electric field strength in the vielectric.

Suggestions for future cable research aid development are given.

\section{INTRODUCTION}

In Controlled Thermonuclear Research (CTR), coaxial cables are used extensively to transmit high voltages. In trigger systems or fast energy transfer systems, yoitages may exceed by orders of magnitude the ratings the manufacturer is willing to put on the cable. Experiments have shown that these ratings are unrealistic and that, provided a few losses are acceptable, the cable will operate satisfactorily at the higher voltages. It is not easy to choose or design such cable because there are several conflicting criteria. Usually the inductance must be low, the size small, and the voltage capability high. We will first examine the probiem of finding the minimum size cable for a given inductance, operating voltage, and maximum electric stress. Under general assumptions, we derive an algorithm that will compute the required cable dimensions. Plots obtained by. using this procedure show how changes in the parameters affect the cable size.

The choice of the maximum electric field and the determination of the operating voltage is then discussed.

\section{OPTIMAL CABLE CALCULATION}

We assume that we know: $L$, the inductance required; $E_{m}$, the maximum allowed electric field in the dielectric; and $v$, the maximum operating voltage. We further assume that the cable is graded; that is, the cable is built with conducting screens outside the inner conductor and inside the outer conductor (Fig. 1). The use of such screens greatly improves the voltage-holding characteristics of the cable. ' In addition, we assume that the maximum radial electric field is essentially equal to $E_{m}$. Bicause

$$
E_{m} \leq \sqrt{\left(E_{r \max }\right)^{2}+\left(E_{z \max }\right)^{2}},
$$

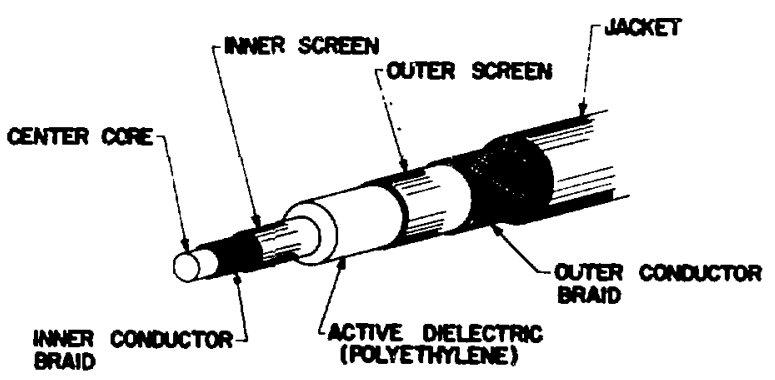

Fig. 1. Screened coaxial cable. 
this is equivalent to assuming that

$$
\left(E_{z \text { max }}\right)^{2} \ll\left(E_{r \text { max }}\right)^{2} \text {. }
$$

The value of $E_{z \max }$ is determined from $L \frac{d I}{d t}$ in the cable. He are not usually interested in cable with inductances greater than $350 \times 10^{-9} \mathrm{H} / \mathrm{m}$ and experience has shown that maximum currents greater than about $20 \times 10^{3} \mathrm{~A}$ are not practical in a single cable. If we further assume that this current rises in times greater than $10^{-8} \mathrm{~s}$, we can estimate the size of $E_{z \text { max. We have }}$

$$
E_{z \max }<\frac{\left(3.5 \times 10^{-7}\right)\left(2 \times 10^{4}\right)}{10^{-8}}=7 \times 10^{5} \mathrm{~V} / \mathrm{m} .
$$

However, polyethyiene can safely operate at fields we 11 in excess of $36 \mathrm{MV} / \mathrm{m}$ (in 17/14 HR cable, $E_{r} \max$ is about $40 \mathrm{MV} / \mathrm{m})$. Using the higher value of $E_{z} \max$ and the sinaller value of $E_{r}$ max , we have

$$
\begin{aligned}
\sqrt{\left(E_{r \cdot \max }\right)^{2}+\left(E_{z \max }\right)^{2}} & =(: 296+0.49)^{1 / 2} \times 10^{6} \\
& =36.0068 \mathrm{MV} / \mathrm{m},
\end{aligned}
$$

which shows that tha replacement of $E_{m}$ by $\left(E_{r \text { max }}\right)$ produces negligib?e error.

The voltage that, the cable die?ectric is required to hold is given by

$$
v=\int_{r_{i}}^{r_{0}} E_{r} d r
$$

where $r_{0}$ is the outer radius of the cable dielectric, $r_{i}$ is the inner radius of the cable dielectric, and $\varepsilon_{r}$ is the radial electric field. In a cylindrical geometry,

$$
E_{r}=\frac{a}{r}
$$

so that

$$
v=a k n \frac{r_{0}}{r_{i}}
$$

Here, a is a constant to be determined. In this we have neglected any voltage drop in the conducting screen and to prove that this is justified, we show that the skin depth in the screen material is large compared to the transverse screen dimension. Measurement shows the resistivity of the screen is

$$
p=1.7 \times 10^{-2} 6 \mathrm{~m} \text {. }
$$

The skin depth is given by

$$
s=\sqrt{\frac{4}{10} \frac{\pi p}{f}}=\sqrt{\frac{\rho}{f} \times 10^{7}} .
$$

Oscillation frequencies of less than $0.5 \times 10^{8} / \mathrm{s}$ are expected therefore,

$$
\mathrm{s}=20.058 \mathrm{~m} .
$$

Because $s$ is at least 50 times greater than the screen thickness, even at very high frequencies, no substantial voltage will appear across the screen.

with these assumptions, the maximum radial electric fielo in the cable is given by

$$
E_{m}=\frac{a}{r_{i}}
$$

The inductance of a coaxial cable is given by

$$
L=2 \times 10^{-7} \operatorname{En} \frac{R_{0}}{R_{i}} \text {, }
$$

where $R_{0}$ and $R_{i}$ are the geometric mean radi $i$ of the inside and outside conductors. We assume that the current is distributed uniformly across the area of the conductors, which is usually the case when braided conductors are used. If the conductors are thick, then corrections for skin depths should be made. In the following discussion we will assume that this geometric mean distance is at the middle radius of the conductor.

Let $s_{i}$ and $s_{0}$ be the thickness of the inner arid cuter screens, respectively. Let $b_{i}$ and $b_{0}$ be the thickness of the iriner and outer conductors. Then

$$
R_{0}=r_{0}+s_{0}+b_{0} / 2 .
$$

and

$$
R_{i}=r_{i}-s_{i}-b_{i} / 2 .
$$

Using these in Eq. (3), we find

$$
r_{0}=\left(r_{i}-s_{i}-b_{i} / 2\right) e^{L / 2 \times 10^{-7}}-s_{0}-b_{0} / 2 \text {. }
$$

We need a second expression relating $r_{0}$ and $r_{i}$. By themselves, $E_{M}, V$. and $L$ do not uniquely determine $r_{n}$ and $r_{i}$. However, we must also have 


$$
\frac{a}{r_{i}} \leq E_{m}
$$

which, using Eq. (1), yields

$$
v=E_{m} r_{i} \approx \frac{r_{0}}{r_{i}} \text {. }
$$

We want to solve Eqs. (6) and (7) subject to the condition that the cable diameter be minimum. This is equivalent to $r_{0}$ being as small as possible. But Eq. (6) implies that if $r_{0}$ is minimal, so is $r_{j}$. then $r_{i}$ is minimal, the maximum electric field will be attained and we can assume equality in Eq. (7).

$$
v=E_{m} r_{i} \approx \frac{r_{0}}{r_{i}} .
$$

Equations (6) and (8) can be combined to give

$$
\begin{aligned}
V / E_{m} & =r_{i} \therefore \frac{1}{r_{i}}\left[r_{i} e^{L / 2 \times 10^{-7}}\right. \\
& \left.-\left(s_{i}+b_{i} / 2\right) e^{L / 2 \times 10^{-7}}-\left(s_{0}+b_{0} / 2 i\right]\right] \\
& =r_{i} \cdots\left(e^{L / 2 \times i_{i}}-k / r_{i}\right),
\end{aligned}
$$

where

$$
K=\left(s_{i}+b_{i} / 2\right) e^{L / 2 \times 10^{-7}}+\left(s_{0}+b_{0} / 2\right) .
$$

We can solve Eq. (9) for $r_{j}$ by iteration. Usiny the Newton-Raphson method, we arrive at the following iterative equations.

$\left(r_{i}\right)_{n+1}=\left(r_{i}\right)_{n}$

$+\frac{\left(v / \varepsilon_{m}-\left(r_{i}\right)_{n} \ldots\left[e^{L / 2 \times) 0^{-7}}-k /\left(r_{i}\right)_{n}\right]\right)}{\left(v i_{i}\left[e^{L / 2 \times 10^{-7}}-k /\left(r_{i}\right)_{n}\right]+k /\left[\left(r_{i}\right)_{n} e^{L / 2 \times 10^{-7}}-k\right]\right)}$,

and

$$
\left(r_{i}\right)_{0}=\frac{V / E_{m}}{\left(V / E_{m}+\frac{s_{i}+b_{i}}{s_{i}}\right)}
$$

We will return to the solution of Eq. (1) in the finat section.

\section{CHOICE OF OPERATING VOLTAGE AND MAXIMUM} FIELD STRENGTH

The peak operating voltage $v$ used in the derivation of Eq. (9) is the maximum potential that will appear across the cable; it is not the oc operating voltage. The determination of $y$ must take into consideration transient pulses producec in the cable or in components connected to it and propagated in the cable. Direct measurement of such voltages is usually not possible. One way to determine $v$ is by computation. For instance, the NET-2 computer program can be used. ${ }^{2,3}$ The cable is treated as a lumped constant ine of more than five sections. The peak voltage appearing is a good estimate of $V$ althougi voltages calculated in this way are usually a few percentage points too high.

The determination of $E_{m}$ is a more complicated situation. The maximum electric field at which the polyethylene can operate satisfactorily is in part determined by how carefully it was extruded. This implies that some knowledge of the manufacturers' past performance would be helpful in deciding which $E_{m}$ to specify. However, given manufacturing uniformity, a lot can be said about the rational determination of $E_{m}$.

Some knowledge about the failure behavior of high 21 tage polyethylene cable is required. When the raw failure data for such cable are plotted on Weibull coordinates, a knee appears at some percentage of failures and at some number of shrits. This characteristic occurs in ac cable, ${ }^{4}$ highvoltage pulse cable, and recently in dc cable. At this knee, the failure rate changes from an increasing function of the number of operations to a decreasing function. The position of this knee can be used to determine $E_{m}$. As $E_{m}$ is increased, the percentage of cables failing berore the kree is reached should increase, wh:?oas the number of operations required shouid decrease. Therefore, if pretesting cannot be done and if the losses must be kept low, $E_{m}$ must be kept low. However, if pretesting can be done and if one is willing to lose a large percentage of cables before installation, then $E_{m}$ can be chosen fairly large. The latter situation is the usual one in much CTR work. Because space is limited, the size of the cable must be small. This forces large $E_{m}$, but by accepting 5 to $15 \%$ preinstallation testing losses, the actual machine can be made reliable with respect to cable failures.

These considerations determine $E_{m}$ qualitatively. At present there is no accurate way to determine $E_{r \text { r. }}$ 
TABLE I

POSITION OF WEIBULL PLOT KNEE FOR CERTAIN CABLES

\begin{tabular}{|c|c|c|c|c|}
\hline Cable & Mfgr & $\begin{array}{l}\text { Losses to } \\
\text { Knee }(\%)\end{array}$ & $E_{m}(M V / m)$ & $v(k v)$ \\
\hline $17 / 14 \mathrm{HR}$ & Plastoid & $\sim 4$ & 39.5 & 110 \\
\hline $17 / 14 \mathrm{HF}$ & Plastoid & $\sim 10-20$ & $42.0-47.0$ & $125-145$ \\
\hline $17 \mathrm{DS}$ & Chester & $\sim 10$ & 43.0 & 135 \\
\hline 17 OS & Plastoid & $\sim 25$ & 43.0 & 135 \\
\hline
\end{tabular}

quantitatively. A research program is needed that would determine the position of the knee as a function of $E_{m}$ and $V$. The preceding $i a b l e ~ g i v e s$ some information obtained from related experiments.

The losses in Table I are cable losses and not losses per unit length. The termination regions of the cable account for a disproportionate fraction of the total if the losses are analyzed on a per foot basis. Probably this occurs vecause termination faults have a different distribution than the bulk of the cable, One object of a research program would be to untangle these two distributions. The reason for the large difference between chester 17 DS and Plastoid 17 DS is not known but could be due to the use of polyethylene from different manufacturers or to different extrusion techniques. A research program probably could clarify this. An irvestigation to determine how the knee position on the Waibull plot varies with the density of the polyethylene would also be of great interest.

From experience with present cable manufacturers, a choice of $\mathrm{E}_{\mathrm{m}}$ at or below $40 \mathrm{MV} / \mathrm{m}$ should lead to reasonably low losses and fairly reliable cable. Higher choires of $E_{m}$ are acceptable only if greater initial cable losses can be tolerated.

\section{DEPENDENCE OF THE OPTIMAL DESIGN ON}

$$
\text { L. } E_{m} \text {, A.ND } v
$$

Equation (10) has teen programmed for solution on a digital computer. Iteration is stopped when the relative difference between $\left(r_{i}\right)_{n}$ and $\left(r_{i}\right)_{n+1}$ is less than $10^{-6}$. When $r_{i}$ is determined, $r_{0}$ is determined from Eq. (6), and all other cable design values ore easily found in an obvious way.

It is of interest to know how the outside diameter of the optinal cable varies as $L, E_{m}$, and $V$ are varied. To this end we choose fixed values of the inner and outer conductor and screen thickness, as well as fixed jacket thickness, and calculate the cable diameter for various values of $L, E_{m}$, and v. Specifically, we choose

$$
\begin{aligned}
& s_{i}=0.000508 \mathrm{~m}, \\
& s_{0}=0.000508 \mathrm{~m}, \\
& b_{i}=0.0005504 \mathrm{~m}, \\
& b_{0}=0.0005504 \mathrm{~m}
\end{aligned}
$$

and

jacket thickness $=0.0009398 \mathrm{~m}$.

Representative results are given in the fami-

lies of curves displayed in Fig. 2 through 15.

Figures 2 through 7 plot diameter vs inductance for families of $E_{m}$ values. Figures 8 througn 11 show plots of diameter $r$ inductance for families of constant $V$. Note that ninima occur in these two sets of curves. Because the cost of the cable should be proportional to the volume of material used, these minima should determine the cable design when inductance is unimportant. Figures 12 throur,h 15 display cable diameter vs $v$ for families of co.1stant inductance. These curves are almost, but not quite, straight lines.

\section{ACKNOWLEDGMENTS}

I am grateful to E. L. Kemp for suggestins the study.

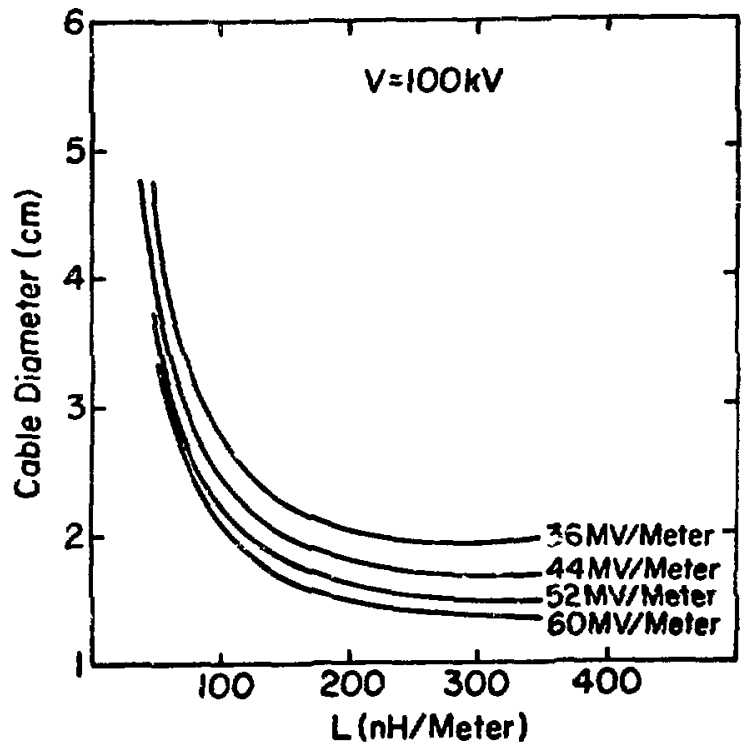

Fig. 2. Cable diameter $s$ inductance - curves of constant $E_{\mathrm{m}^{\circ}} \quad V=100 \mathrm{kV}$. 


\section{REFERENCES}

1. G. P. Boicourt and E. L. Kemp, "The Development of Reliable, High-Voltage, Low-Inductance Cable for Scyllac," in "Proceedings of Symposium on Eng ineering Problems of Fusion Research," Los Alamos, New Mexico, April 8-11, 1969, Los Alamos Scientific Laboratory report $L A-4250$ (January 1970).

2. Allen F. Malmberg, "issers Manual NET-2 Network Analys is Program," AD-752600, Braddock, Dunn and McDonald, Inc., El Paso, Texas (October 1973).

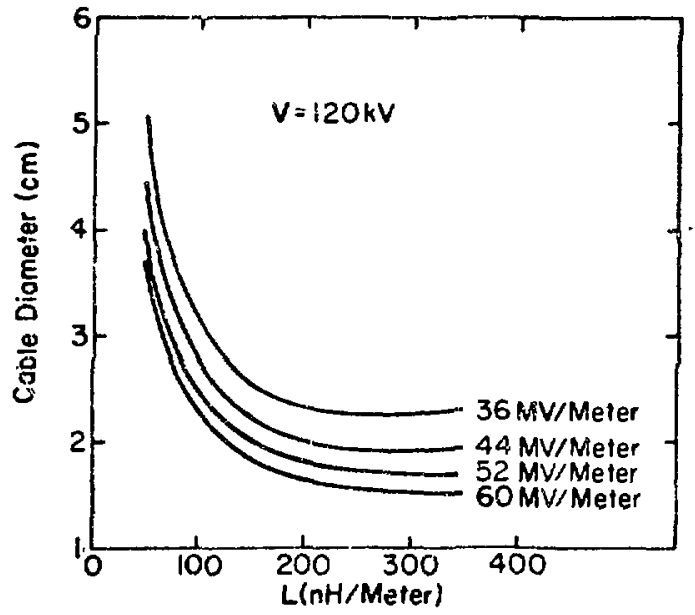

Fig. 3. Cable diamiter vs inductance - curves of constant $\ddot{t}_{m^{\prime}}, \quad V=120 \mathrm{kV}$.
3. G. P. Boicourt, "Application of the MET-1 Network Analysis Program to Distributed Circuits," in "Proceedings of Symposium on Engineering Problems of Fusion Research," Los Alamos, New Mexico, April 8-11, 1969, Los Alamos Scientific Laboratory report LA-4250 (January 1970).

A. r. ii. Kreuger, "Endurance Tests with Polyetriylene Cables," in Proceedings 22nd Session Conference Interriational des Grands Réseaux Electriques a Haute Tension (CIGRE), LNESCO, Paris, August 1968, Group 21, Paper No. 02.

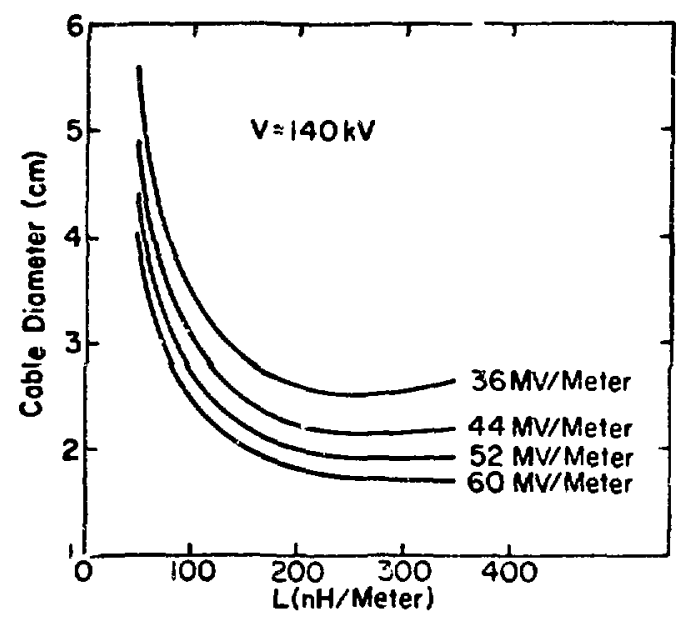

Fig. 4. Cable diameter vs indur-cance - curves of constant $E_{m^{\circ}} V=140 \mathrm{kV}$. 


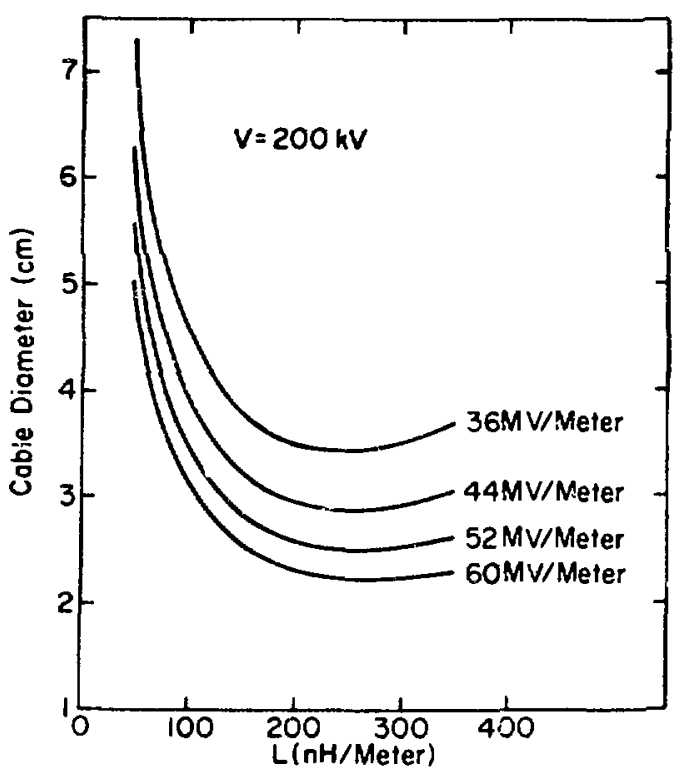

Fig. 5. Cable diameter vs inductance - curves of constant $E_{m^{\circ}} \quad V=200 \mathrm{kV}$.

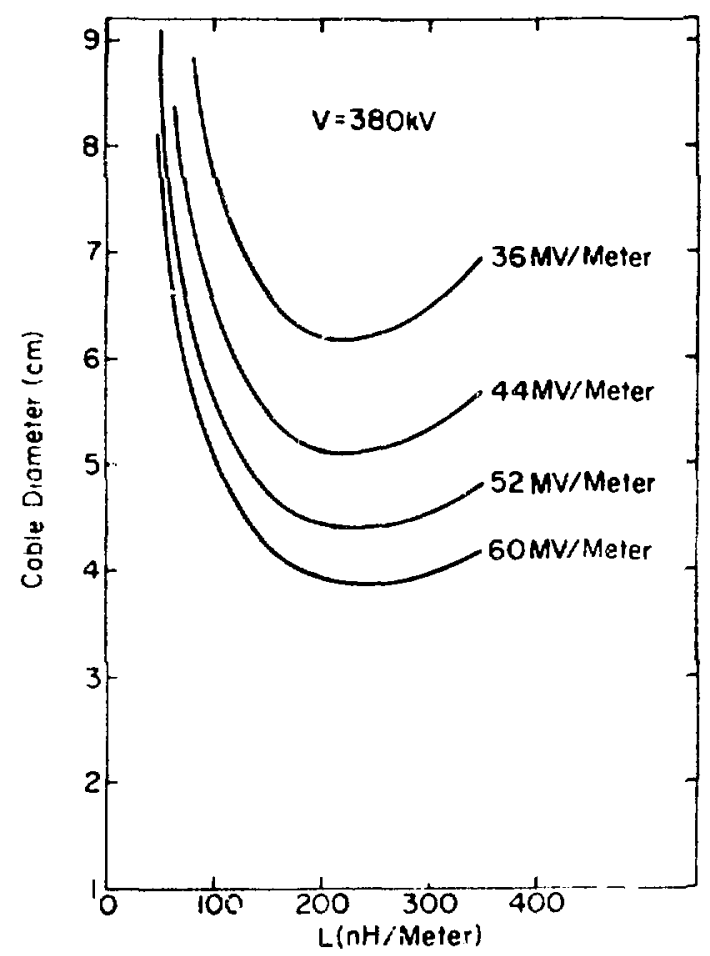

Fig. 7. Cable diameter vs inductance - curves of constant $\mathrm{E}_{\mathrm{m}} \cdot \mathrm{V}=380 \mathrm{kV}$.

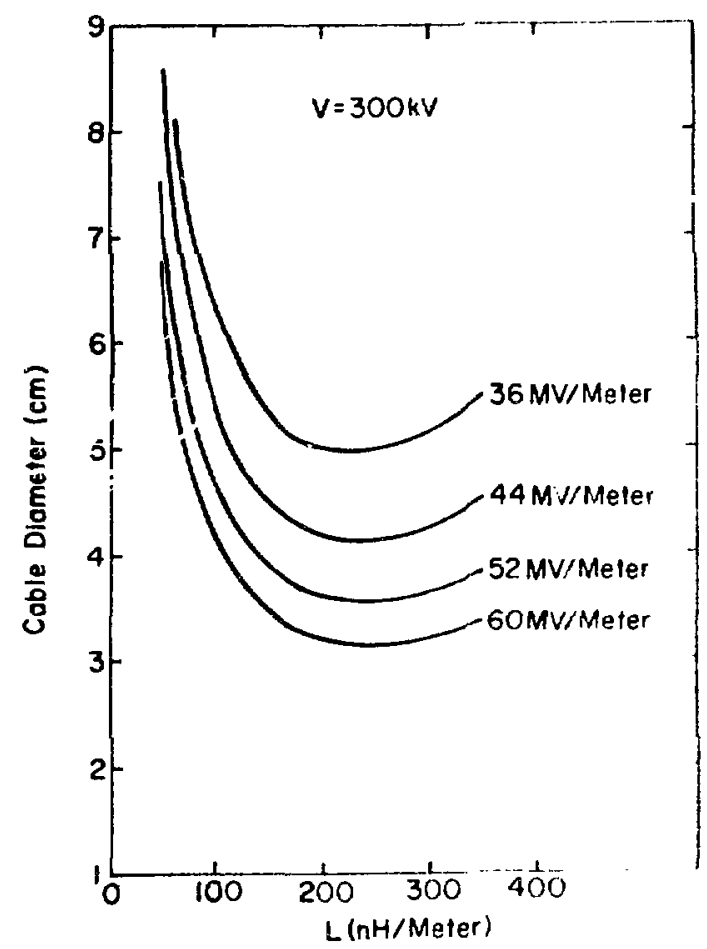

Fig. 6. Cable diameter vs inductance - curves iff constant $E_{m} \cdot V=300 \mathrm{kV}$.

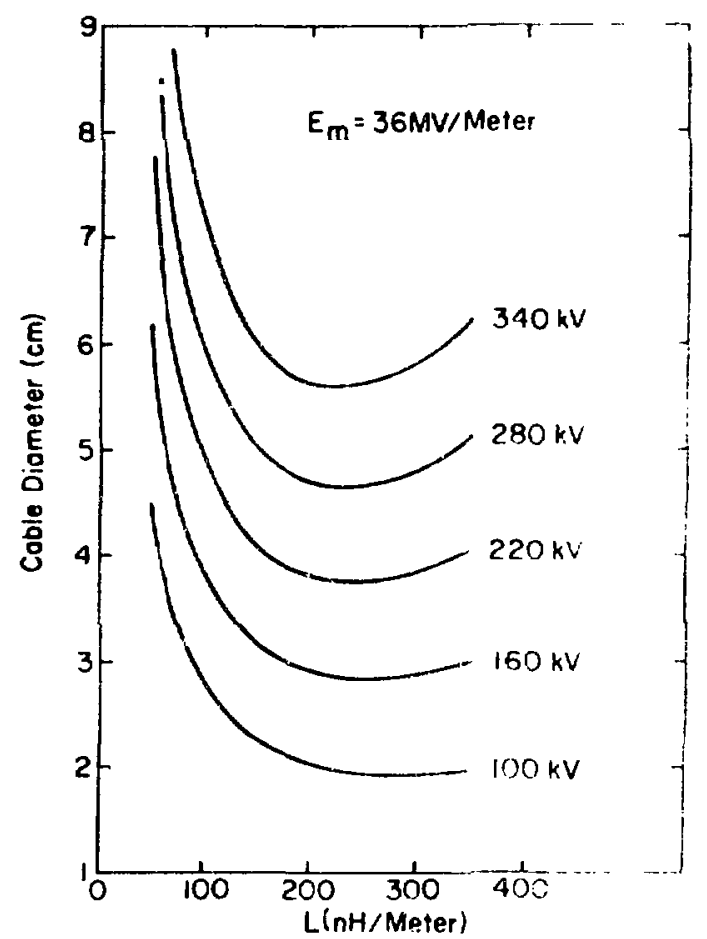

Fig. 8. Cable diameter vs inductance - curves of constant V. $E_{m}=36 \mathrm{MV} / \mathrm{m}$. 


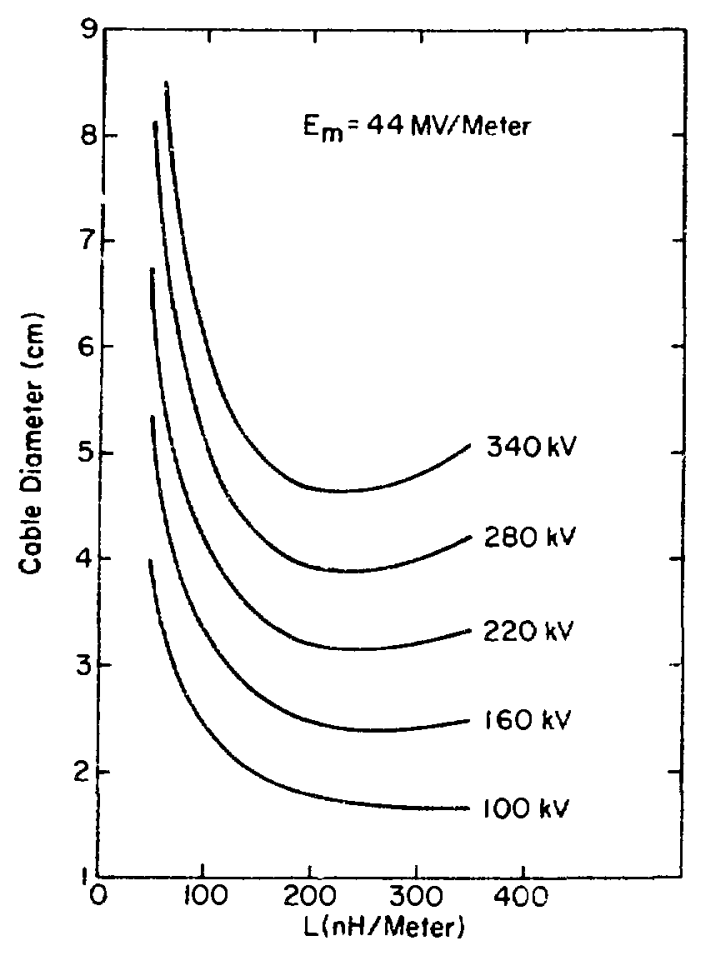

Fig. 9. Cable diameter vs inductance - curves of constant $V . E_{m}=44 \mathrm{Al} /$ m.

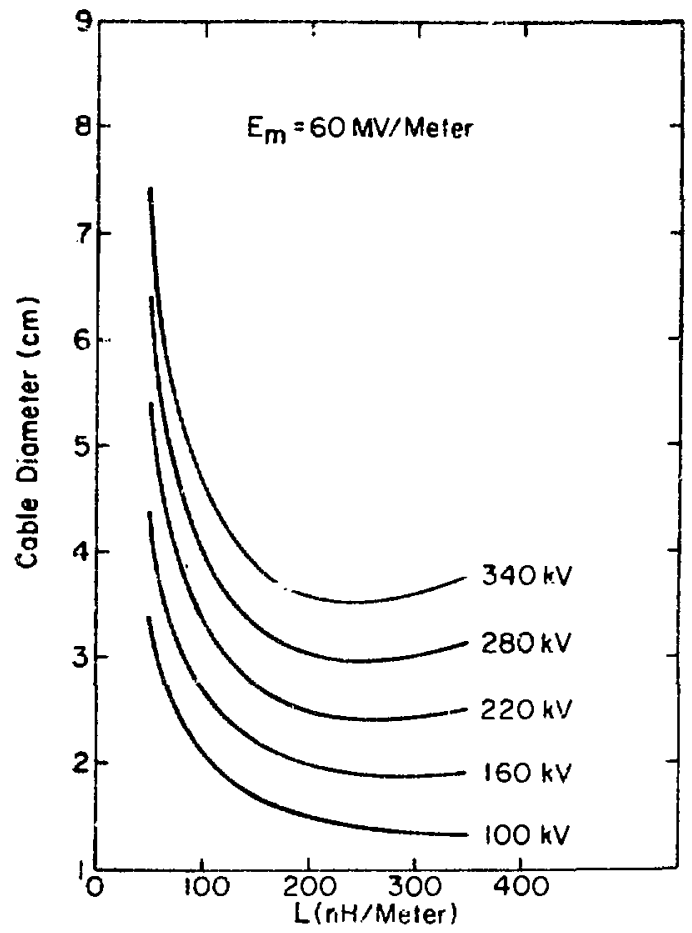

Fig. 11. Cable diameter vs inductance - curves of consiant V. $E_{m}=60 \mathrm{MV} / \mathrm{m}$.

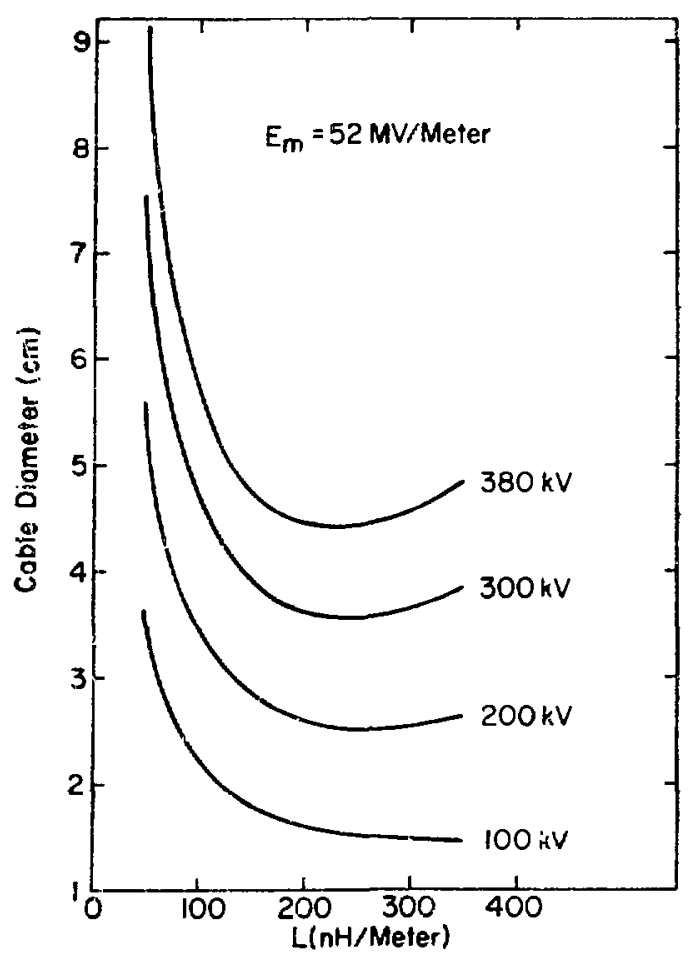

Fig. 10. Cable diameter vs inductance - curves of constant $V . E_{m}=52 \mathrm{MV} / \mathrm{m}$.

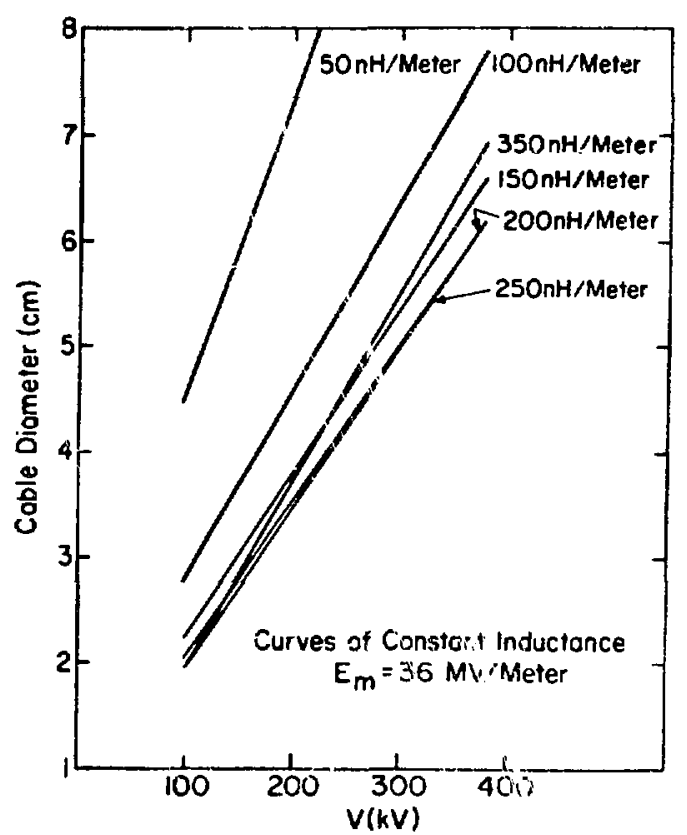

Fig. 12. Cable diameter vs $V$ - curves of constant inductance. $E_{m}=36 \mathrm{MV} / \mathrm{m}$. 

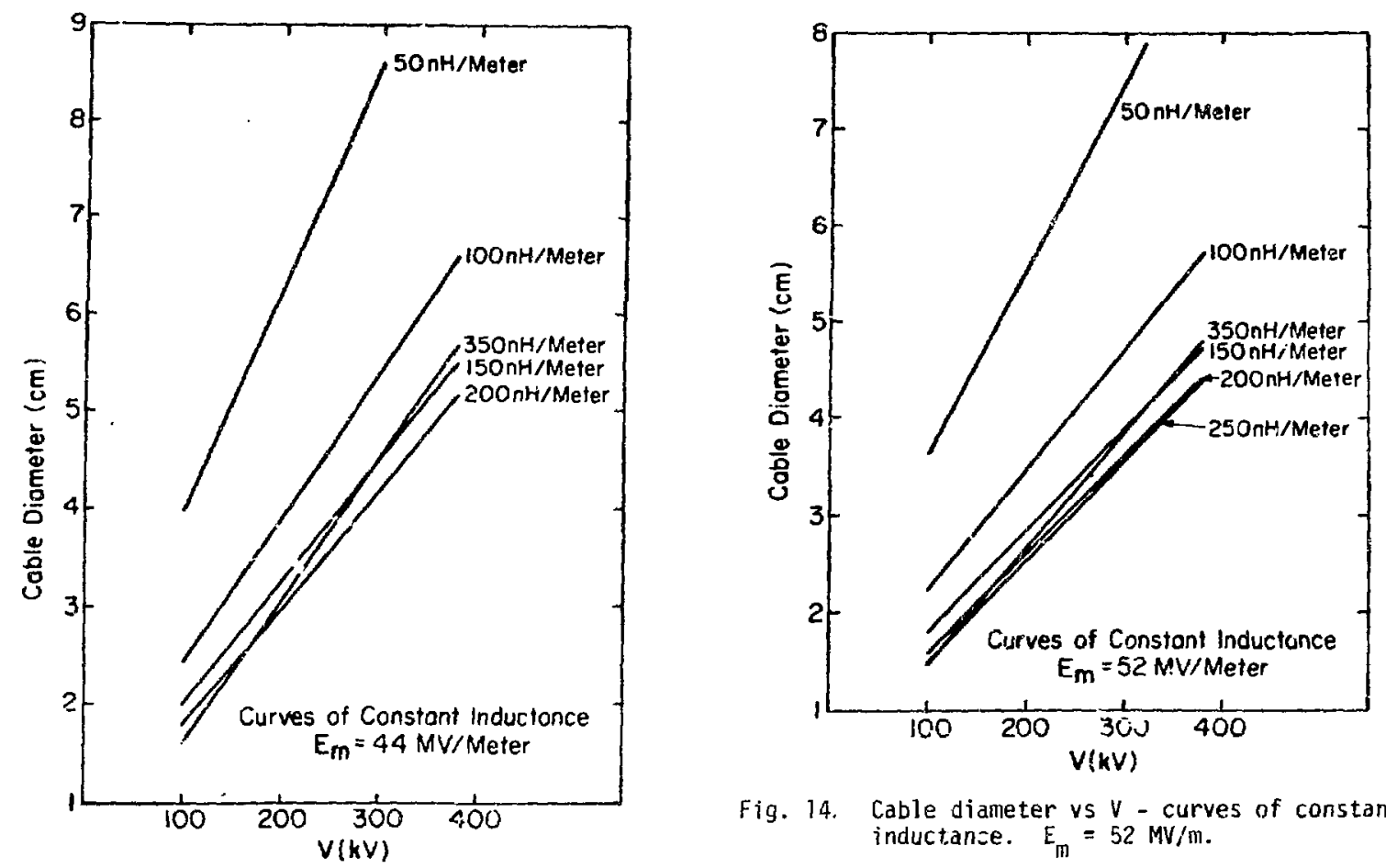

Fig. 14. Cable diameter vs $V$ - curves of constant inductance. $E_{m}=52 \mathrm{MV} / \mathrm{m}$.

Fig. 13. Cable diameter vs $v$ - curves of coristant inductance. $E_{m}=44 \mathrm{MV} / \mathrm{m}$.

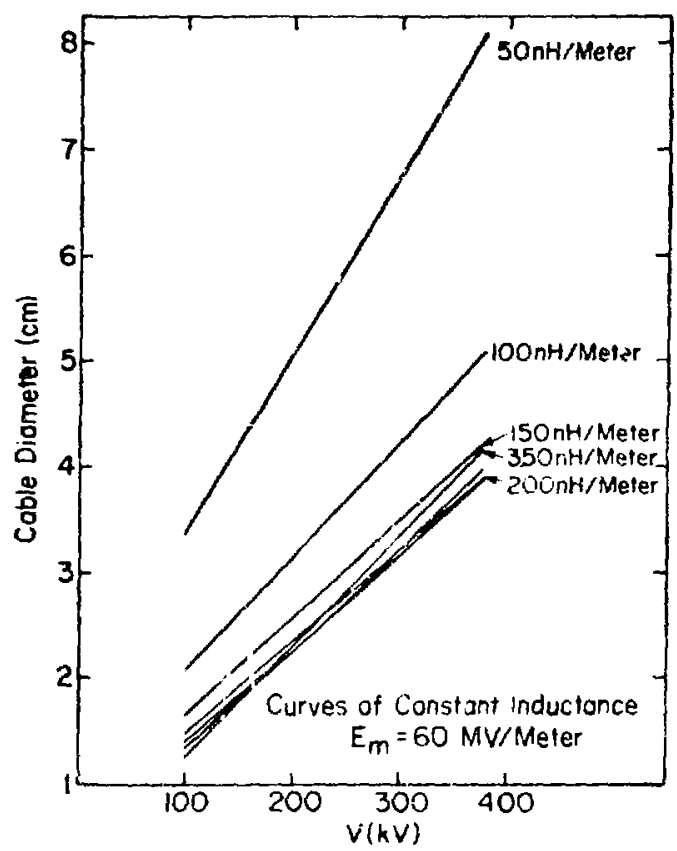

Fig. 15. Cable dianteler vs $v$ - curves of constait inductan:e. $i_{111}=60 \mathrm{MV}$ : ill.

ALT: $286(60)$ 